Article

\title{
Apple Flavonols Mitigate Adipocyte Inflammation and Promote Angiogenic Factors in LPS- and Cobalt Chloride-Stimulated Adipocytes, in Part by a Peroxisome Proliferator-Activated Receptor- $\gamma$-Dependent Mechanism
}

\author{
Danyelle M. Liddle, Meaghan E. Kavanagh ${ }^{\mathbb{D}}$, Amanda J. Wright and Lindsay E. Robinson * \\ Department of Human Health and Nutritional Sciences, University of Guelph, Guelph, ON N1G 2W1, Canada; \\ dliddle@uoguelph.ca (D.M.L.); kavanagh.meaghan.e@gmail.com (M.E.K.); ajwright@uoguelph.ca (A.J.W.) \\ * Correspondence: lrobinso@uoguelph.ca; Tel.: +1-519-824-4120 (ext. 52297)
}

Received: 6 April 2020; Accepted: 6 May 2020; Published: 12 May 2020

\begin{abstract}
Adipose tissue (AT) expansion induces local hypoxia, a key contributor to the chronic low-grade inflammation that drives obesity-associated disease. Apple flavonols phloretin (PT) and phlorizin (PZ) are suggested anti-inflammatory molecules but their effectiveness in obese AT is inadequately understood. Using in vitro models designed to reproduce the obese AT microenvironment, 3T3-L1 adipocytes were cultured for $24 \mathrm{~h}$ with PT or PZ $(100 \mu \mathrm{M})$ concurrent with the inflammatory stimulus lipopolysaccharide (LPS; $10 \mathrm{ng} / \mathrm{mL}$ ) and/or the hypoxia mimetic cobalt chloride $\left(\mathrm{CoCl}_{2} ; 100 \mu \mathrm{M}\right)$. Within each condition, PT was more potent than PZ and its effects were partially mediated by peroxisome proliferator-activated receptor (PPAR)- $\gamma(p<0.05)$, as tested using the PPAR- $\gamma$ antagonist bisphenol A diglycidyl ether (BADGE). In LPS-, $\mathrm{CoCl}_{2^{-}}$, or LPS $+\mathrm{CoCl}_{2}$-stimulated adipocytes, PT reduced mRNA expression and/or secreted protein levels of inflammatory and macrophage chemotactic adipokines, and increased that of anti-inflammatory and angiogenic adipokines, which was consistent with reduced mRNA expression of M1 polarization markers and increased M2 markers in RAW 264.7 macrophages cultured in media collected from LPS $+\mathrm{CoCl}_{2}$-simulated adipocytes $(p<0.05)$. Further, within LPS $+\mathrm{CoCl}_{2}$-stimulated adipocytes, PT reduced reactive oxygen species accumulation, nuclear factor- $\kappa \mathrm{B}$ activation, and apoptotic protein expression $(p<0.05)$. Overall, apple flavonols attenuate critical aspects of the obese AT phenotype.
\end{abstract}

Keywords: adipocyte; flavonols; hypoxia; inflammation; obesity

\section{Introduction}

In diet-induced obesity, adipose tissue (AT) expansion is accompanied by metabolic dysfunction [1]. Several mechanisms have been proposed to explain the pathogenesis of obese AT dysfunction, including dysregulated adipocyte production of inflammatory adipokines (e.g., interleukin (IL)-1 $\beta$ and IL-6, monocyte chemoattractant protein (MCP)-1, tumor necrosis factor (TNF)- $\alpha$ ) [2] via activation of toll-like receptor 4 (TLR4) by dietary saturated fatty acids (SFA) [3], or dysbiotic gut-derived endotoxin (i.e., lipopolysaccharide (LPS)) [4], the induction of metabolic stress [5] and increased activities of reactive oxygen species (ROS) [6], and the activation and consequent paracrine interactions with specific immune cell populations, particularly M1 macrophages [7]. A common intermediate amongst these mechanisms is activation of the nuclear factor kappa-light-chain-enhancer of activated B cells (NF- $\mathrm{kB}$ ) transcription factor that regulates inflammatory adipokine expression $[1,8]$. Indeed, obesity is recognized as a chronic low-grade inflammatory state that drives the development of insulin resistance, a precursor to metabolic diseases such as type 2 diabetes (T2D) and cardiovascular disease (CVD) [8]. 
Another causative factor underlying obese AT inflammation is hypoxia [9]. When hypertrophic adipocyte size exceeds the diffusional limit of oxygen from the blood [10], the low oxygen tension induces both NF- $\mathrm{kB}$ and hypoxia-inducible factor (HIF)-1 accumulation [11-13]. As a transcription factor, HIF-1 regulates the adipocyte molecular response to hypoxia, mainly promoting gene expression of angiogenic adipokines (e.g., vascular endothelial growth factors (VEGF), angiopoietin-like peptides (Angptl), and leptin) to form new blood vessels [11,12]. However, in obese AT, the rate of angiogenesis is not sufficient to supply hypertrophic adipocytes with enough oxygen and nutrients [14], eventually leading to adipocyte apoptosis [15]. In response, certain immune cells (particularly macrophages) are recruited to AT to remove the cellular debris [16]; however, the increased and sustained immune cell infiltration and paracrine signaling with adipocytes drives local AT inflammation, leading to its dysfunction [17]. In this context, hypoxia may be an early event responsible for the initiation of AT inflammation and dysfunction, and strategies aimed at mitigating this sequence of events are warranted.

One possible dietary strategy is the intake of flavonoids, a group of plant-derived phenolic compounds associated with a reduced risk of metabolic diseases [18]. Of all fruit and vegetable flavonoid sources, apples are reportedly the most consumed in the Western diet [19] and have been consistently associated with a reduced risk of T2D and CVD [20]. Phlorizin (PZ), yielding the aglycone phloretin (PT), is the major dihydrochalcone flavonoid found in apples, primarily in the peel [21]. PT has been shown to promote adipogenic mRNA transcription via the peroxisome proliferator-activated receptor (PPAR)- $\gamma$ transcription factor which also regulates the transcription of the anti-inflammatory adipokine adiponectin [22] and angiogenic adipokines [23]. Indeed, both PT and PZ have been shown to exert anti-inflammatory and anti-oxidant activities in vitro [22,24-27] and in vivo [28,29], but these effects and the underlying mechanisms have not been studied in the context of the obese AT inflammatory and hypoxic microenvironment. Thus, the purpose of this study was to investigate the effects of PT and PZ in modulating the adipocyte response to inflammatory and hypoxic stimuli, as well as their consequent effects on macrophage polarization, and to discern the role of PPAR- $\gamma$ in mediating those responses.

\section{Materials and Methods}

\subsection{Cell Culture and Differentiation}

3T3-L1 murine pre-adipocytes (American Type Culture Collection (ATCC), USA) were cultured and differentiated according to the manufacturer's instructions, as previously described [30]. Adipocytes were treated as described below eight days after differentiation was induced, when complete differentiation had occurred.

\subsection{Treatments}

All treatments were performed in triplicate and replicated independently three times (i.e., $n=9 /$ treatment). All cells were treated for $24 \mathrm{~h}$ with $100 \mu \mathrm{M}$ of the apple flavonols PT or PZ (from apple wood, $\geq 99 \%$ pure; Sigma-Aldrich, St. Louis, MO, USA) in combination with $10 \mathrm{ng} / \mathrm{mL}$ of the inflammatory stimulus LPS (from Escherichia coli 055:B5; Sigma-Aldrich) or $100 \mu \mathrm{M}$ of the hypoxia mimetic cobalt chloride $\left(\mathrm{CoCl}_{2}\right.$; Sigma-Aldrich) [11,12], or in combination with both LPS + $\mathrm{CoCl}_{2}$. PT and PZ were dissolved in lab-grade ethanol and LPS was dissolved in fetal bovine serum-free media. For PT and PZ, $100 \mu \mathrm{M}$ was chosen as the optimal dose shown to modulate adipocyte gene expression when in co-culture with macrophages, without affecting cell viability [26]. Further, $100 \mu \mathrm{M}$ PT is reportedly representative of the maximum concentration of total PT that was achieved in the plasma of PT- and PZ-red rodents [31]. We chose $10 \mathrm{ng} / \mathrm{mL}$ of LPS to mimic circulating endotoxin levels in obese humans [32] and rodents [4]. For $\mathrm{CoCl}_{2}$, we chose $100 \mu \mathrm{M}$ to mimic the effects of low (1\%) oxygen tension in adipocytes over $24 \mathrm{~h}$ without affecting cell viability [12]. Unstimulated adipocytes served as the negative control for each culture condition. To investigate the mechanism by which 
PT and PZ exert their effects, a PPAR- $\gamma$ antagonist, bisphenol A diglycidyl ether (BADGE; Cayman Chemical, Ann Arbor, MI, USA) was added to a subset of each culture condition. BADGE was diluted in lab-grade ethanol and added to culture wells at $100 \mu \mathrm{M}$, as described [33]. Cell viability, assessed by trypan blue exclusion, exceeded $90 \%$ for all culture conditions, which was supported by no differences in total cellular protein content compared to unstimulated adipocytes. After $24 \mathrm{~h}$, supernatant samples were collected, and cells were lysed to isolate RNA and protein using the RNA/Protein Purification Kit as per the manufacturer's instructions (Norgen Biotek Corp., Thorold, ON, Canada).

\subsection{RAW 264.7 Macrophages Treated with LPS $+\mathrm{CoCl}_{2}$-Stimulated Culture Conditioned Media}

RAW 264.7 macrophages (ATCC) were maintained according to the manufacturer's instructions, as previously described [34]. Macrophages were split, centrifuged and resuspended in fresh media $4 \mathrm{~h}$ prior to treatment with conditioned media from LPS $+\mathrm{CoCl}_{2}$-stimulated cultures \pm BADGE ( $n=9$ /treatment). Cell viability, assessed by trypan blue exclusion, exceeded $95 \%$. We seeded $1 \times 10^{5}$ macrophages into 96-well plates and allowed them to adhere before being cultured in conditioned media. After $6 \mathrm{~h}$, supernatant samples were collected, and macrophages were lysed to isolate RNA.

\section{4. $m R N A$ and Secreted Protein Analyses}

We used $2 \mu \mathrm{g}$ of isolated RNA from all adipocyte and macrophage cultures to synthesize cDNA using a high-capacity cDNA reverse transcription kit (Applied Biosystems, Foster City, CA, USA) and real time polymerase chain reaction was performed using the 7900HT Fast Real Time PCR system (Applied Biosystems), as described [34]. Target gene expression was normalized to expression of the housekeeping gene, ribosomal protein, large, P0 (Rplp0), and the relative differences in gene expression between groups were determined using the $\Delta \Delta \mathrm{Ct}$ method in comparison to unstimulated adipocytes. Primer sequences for inflammatory (Il1 $\beta, I l 6, M c p 1$, Tnfo), anti-inflammatory (adiponectin, Il10), and angiogenic (Angptl4, leptin, Vegfa) adipokines, additional M1 (cluster of differentiation (Cd)11b, $C d 11 c$, inducible nitric oxide synthase (iNos)) and M2 (Cd206, transforming growth factor (Tgf) $\beta)$ macrophage polarization markers, and related transcription factors (Hif1 $\alpha, N f \kappa b$, Ppar $\gamma$ ) are shown in the Supplemental Materials Table S1. All reported fold-changes are relative to unstimulated adipocytes.

\subsection{Secreted Protein Analysis}

Secreted protein concentrations of inflammatory (IL-1 $\beta$, IL-6, TNF- $\alpha$ ), anti-inflammatory (adiponectin, IL-10), macrophage chemotactic (MCP-1, MCP-3, macrophage inflammatory protein (MIP)-1 $\alpha$, MIP-1 $\beta$ ), and angiogenic (Angptl4, leptin, VEGF-A) adipokines were measured in supernatant samples collected at $24 \mathrm{~h}$ from LPS $+\mathrm{CoCl}_{2}$-stimulated cultures using a Mouse Cytokine/Chemokine Bio-Plex Pro kit (Bio-Rad, Mississauga, ON, Canada) and analyzed using the Bio-Plex 200 system/Bio-Plex Manager software Version 6.0 (Bio-Rad).

\subsection{ROS Accumulation}

ROS was detected in LPS $+\mathrm{CoCl}_{2}$-stimulated cultures ( $n=9 /$ treatment $)$ at $24 \mathrm{~h}$ by a nitro blue tetrazolium (Sigma-Aldrich) assay, as previously described [30].

\subsection{NF-אB p65 Activation}

Total cellular protein was quantified using the bicinchoninic assay according to the manufacturer's instructions (Fisher Scientific, Mississauga, ON, Canada) and an equal amount of protein $(10 \mu \mathrm{g}) / \mathrm{sample}$ was utilized. NF-kB p65 activation was determined in LPS $+\mathrm{CoCl}_{2}$-stimulated cultures from the ratio of phosphorylated (i.e., activated) NF- $\mathrm{kB}$ p65 (Ser536) to total NF- $\mathrm{kB}$ p65 by enzyme-linked immunosorbent assay as per the manufacturer's instructions (eBioscience, San Diego, CA, USA). 


\subsection{Cellular Apoptotic Protein Analysis}

Cellular levels of the B-cell lymphoma 2 (BCL-2) protein family including apoptotic (BCL-2-associated agonist of cell death (BAD), BCL-2-like protein 11 (BIM)) and anti-apoptotic (BCL-2/BCL-2-like protein 4 (BAX), B-cell lymphoma-extra-large (BCL-XL), induced myeloid leukemia cell differentiation protein (MCL-1)) proteins were measured in LPS $+\mathrm{CoCl}_{2}$-stimulated cultures at $24 \mathrm{~h}$ using a Mouse Bio-Plex Pro Apoptosis kit (Bio-Rad) and analyzed using the Bio-Plex 200 system/Bio-Plex Manager software, Version 6.0 (Bio-Rad).

\subsection{Statistical Analysis}

All statistical analyses were performed using the Statistical Analysis System, University Edition (SAS Institute Inc., Cary, NC, USA) with $p<0.05$ considered statistically significant. Data collected from LPS, $\mathrm{CoCl}_{2}$, and LPS + $\mathrm{CoCl}_{2}$-stimulated adipocytes were compared to data collected from unstimulated adipocytes using unpaired $t$-tests to confirm the adipocyte inflammatory and/or hypoxic response in each model (data not shown). Data collected from each culture condition were analyzed using a two-way ANOVA for the main effects of flavonol and BADGE treatment. The Shapiro-Wilk test confirmed normality for all endpoints and the Tukey post-hoc test was used to identify significant differences between groups. Replicate experiments were averaged and expressed as means \pm standard error of the mean (SEM).

\section{Results}

\subsection{PT and PZ Modulate Adipokine mRNA Expression in LPS-Stimulated Adipocytes, in Part by a} PPAR- $\gamma$-Dependent Mechanism

To determine the effects of PT and PZ in modulating the adipocyte response to obese AT inflammation, PT- and PZ-treated adipocytes were co-stimulated for $24 \mathrm{~h}$ with a physiological dose of LPS. Compared to LPS-stimulated adipocytes, PT reduced mRNA expression of leptin, Il1 $\beta$, Il6 and Mcp1, while PZ less potently reduced only Il6 and Mcp1 ( $p<0.05$; Table 1). Both PT and PZ increased adiponectin mRNA expression ( $p<0.05$; Table 1) with PT being more potent, while neither affected Vegfa, Angptl4, Tnf $\alpha$, Il10, Hif1 $\alpha$, Nfkb, or Ppar $\gamma$ mRNA levels ( $p>0.05$; Table 1). Interestingly, in LPS-stimulated adipocytes, PPAR- $\gamma$ antagonism with BADGE further increased leptin expression $(p<0.05$; Table 1$)$ but did not affect any other analytes $(p>0.05$; Table 1$)$. The anti-inflammatory effects of PT and PZ were completely reversed by BADGE $(p<0.05$; Table 1$)$ with the exception of $I l 1 \beta$ in PT-treated adipocytes wherein BADGE only partially reversed this anti-inflammatory effect $(p<0.05$; Table 1). Collectively, these data highlight the anti-inflammatory effects of PT and PZ as well as the superior effectiveness of PT in adipocytes, and point to the central role of PPAR- $\gamma$ in mediating these effects.

Table 1. mRNA expression in lipopolysaccharide (LPS)-stimulated adipocytes treated with phloretin (PT) or phlorizin (PZ), with and without bisphenol A diglycidyl ether (BADGE) ${ }^{1}$.

\begin{tabular}{|c|c|c|c|c|c|c|}
\hline \multirow{2}{*}{ Gene } & No Flavonols & PT & $\mathbf{P Z}$ & No Flavonols & PT & PZ \\
\hline & \multicolumn{3}{|c|}{-BADGE } & \multicolumn{3}{|c|}{ +BADGE } \\
\hline \multicolumn{7}{|c|}{ Inflammatory adipokines } \\
\hline $\mathrm{Il} 1 \beta$ & $2.25 \pm 0.07^{\mathrm{a}}$ & $1.95 \pm 0.07^{b}$ & $1.98 \pm 0.03^{b}$ & $2.27 \pm 0.08^{a}$ & $2.16 \pm 0.04^{\mathrm{b}, *}$ & $2.24 \pm 0.05^{\mathrm{a}}$ \\
\hline Il6 & $2.69 \pm 0.08^{a}$ & $0.94 \pm 0.06^{b}$ & $1.25 \pm 0.05^{c}$ & $2.71 \pm 0.09$ & $2.58 \pm 0.05 *$ & $2.67 \pm 0.06^{*}$ \\
\hline Mcp1 & $5.40 \pm 0.16^{\mathrm{a}}$ & $1.89 \pm 0.11^{b}$ & $2.52 \pm 0.10^{c}$ & $5.43 \pm 0.18$ & $5.36 \pm 0.13 *$ & $5.36 \pm 0.13 *$ \\
\hline $\operatorname{Tnf} \alpha$ & $1.06 \pm 0.03$ & $0.99 \pm 0.03$ & $1.00 \pm 0.04$ & $1.01 \pm 0.03$ & $1.04 \pm 0.05$ & $1.00 \pm 0.03$ \\
\hline \multicolumn{7}{|c|}{ Anti-inflammatory adipokines } \\
\hline Adiponectin & $0.77 \pm 0.03^{a}$ & $1.39 \pm 0.02^{b}$ & $1.21 \pm 0.04^{\mathrm{c}}$ & $0.79 \pm 0.03$ & $0.84 \pm 0.02 *$ & $0.83 \pm 0.03 *$ \\
\hline Il10 & $1.06 \pm 0.04$ & $1.01 \pm 0.02$ & $0.98 \pm 0.03$ & $1.01 \pm 0.02$ & $1.01 \pm 0.03$ & $0.97 \pm 0.03$ \\
\hline \multicolumn{7}{|c|}{ Angiogenic factors } \\
\hline Vegfa & $1.23 \pm 0.05$ & $1.27 \pm 0.04$ & $1.24 \pm 0.04$ & $1.26 \pm 0.04$ & $1.26 \pm 0.08$ & $1.25 \pm 0.05$ \\
\hline Angptl4 & $1.21 \pm 0.05$ & $1.20 \pm 0.03$ & $1.20 \pm 0.02$ & $1.21 \pm 0.03$ & $1.21 \pm 0.06$ & $1.21 \pm 0.04$ \\
\hline Leptin & $2.56 \pm 0.13^{a}$ & $1.72 \pm 0.11^{b}$ & $2.51 \pm 0.13^{a}$ & $2.93 \pm 0.14$ * & $2.88 \pm 0.09 *$ & $2.84 \pm 0.05$ * \\
\hline
\end{tabular}


Table 1. Cont.

\begin{tabular}{ccccccc}
\hline \multirow{2}{*}{ Gene } & No Flavonols & PT & PZ & No Flavonols & PT & PZ \\
\cline { 2 - 6 } & \multicolumn{7}{c}{-BADGE } & +BADGE \\
\hline Transcription factors & $1.05 \pm 0.03$ & $0.98 \pm 0.03$ & $1.00 \pm 0.04$ & $1.00 \pm 0.03$ & $1.03 \pm 0.05$ & $0.99 \pm 0.03$ \\
Hif1 $\alpha$ & $1.28 \pm 0.07$ & $1.31 \pm 0.05$ & $1.36 \pm 0.05$ & $1.34 \pm 0.07$ & $1.30 \pm 0.10$ & $1.38 \pm 0.07$ \\
Nfkb & $1.08 \pm 0.04$ & $1.10 \pm 0.03$ & $1.03 \pm 0.02$ & $1.05 \pm 0.03$ & $1.03 \pm 0.02$ & $0.99 \pm 0.02$ \\
Ppar $\gamma$ &
\end{tabular}

${ }^{1}$ Values are means \pm standard error of the mean (SEM); $n=9 /$ culture condition. Data were normalized to $R p l p 0$ mRNA expression and are presented as fold-changes relative to unstimulated adipocytes. Data were analyzed by two-way ANOVA. Means without a common letter differ within cultures treated \pm BADGE, $p<0.05 .{ }^{*}$ Different from -BADGE, $p<0.05$.

\subsection{PT and PZ Modulate Adipokine mRNA Expression in $\mathrm{CoCl}_{2}$-Stimulated Adipocytes, in Part by a PPAR- $\gamma$-Dependent Mechanism}

To determine the effects of PT and PZ in modulating the adipocyte response to obese AT hypoxia, PT- and PZ-treated adipocytes were co-stimulated for $24 \mathrm{~h}$ with the hypoxia mimetic $\mathrm{CoCl}_{2}$. In general, compared to LPS-stimulated cultures, $\mathrm{CoCl}_{2}$ increased the adipocyte angiogenic and inflammatory response $(p<0.05$; Table 1 ; Table 2$)$. Within $\mathrm{CoCl}_{2}$-stimulated cultures and compared to $\mathrm{CoCl}_{2}$-stimulation alone, PT reduced mRNA expression of leptin, Il1 $\beta, I l 6, M c p 1$, and $\mathrm{N} f k b$, and increased that of Vegfa, Angptl4, adiponectin, and Ppar $(p<0.05$; Table 2), with no effect on Tnfo, Il10, or Hif1 $\alpha$ ( $p>0.05$; Table 2). Likewise, PZ reduced mRNA expression of leptin, Il1 $\beta$, Il6, and Mcp1, and increased Vegfa and adiponectin ( $p<0.05$; Table 2), but with less potency compared to PT $(p<0.05$; Table 2). PZ did not affect Angptl4, Tnf $\alpha$, Il10, Hif1 $\alpha, N f \kappa b$, or Ppar $\gamma$ mRNA levels ( $p>0.05$; Table 2). Interestingly, PPAR- $\gamma$ inhibition with BADGE further increased leptin and $N f \kappa b$ mRNA expression in $\mathrm{CoCl}_{2}$-stimulated adipocytes $(p<0.05$; Table 2$)$ but did not affect any other analytes $(p>0.05$; Table 2$)$. The angiogenic and anti-inflammatory effects of PT on leptin, adiponectin, $N f \kappa b$, and Ppar $\gamma$ mRNA expression were totally reversed by BADGE $(p<0.05$; Table 2), whereas the effects on Vegfa, Angptl4, $I l 1 \beta$, Il6, and Mcp 1 were only partially reversed ( $p<0.05$; Table 2$)$. Finally, the effects of PZ were totally reversed by BADGE with the exception of leptin mRNA expression, which was only partially reversed ( $p<0.05$; Table 2). Collectively, these data highlight the anti-inflammatory and angiogenic effects of PT and PZ in adipocytes under hypoxic conditions, as well as the superior effectiveness of PT. Further, these data point to the central role of PPAR- $\gamma$ in mediating the effects of PZ and suggest an additional, PPAR- $\gamma$-independent mechanism through which PT exerts its anti-inflammatory and angiogenic effects in hypoxic adipocytes.

Table 2. mRNA expression in $\mathrm{CoCl}_{2}$-stimulated adipocytes treated with $\mathrm{PT}$ or PZ, with and without BADGE $^{1}$.

\begin{tabular}{|c|c|c|c|c|c|c|}
\hline \multirow{2}{*}{ Gene } & No Flavonols & PT & PZ & No Flavonols & PT & $\mathbf{P Z}$ \\
\hline & \multicolumn{3}{|c|}{-BADGE } & \multicolumn{3}{|c|}{ +BADGE } \\
\hline \multicolumn{7}{|c|}{ Inflammatory adipokines } \\
\hline $\mathrm{Il} 1 \beta$ & $5.96 \pm 0.24^{\mathrm{a}}$ & $2.93 \pm 0.09^{b}$ & $5.39 \pm 0.16^{c}$ & $5.96 \pm 0.14^{\mathrm{a}}$ & $3.78 \pm 0.06^{b, *}$ & $5.95 \pm 0.13^{\mathrm{a}, *}$ \\
\hline Il6 & $5.03 \pm 0.20^{\mathrm{a}}$ & $2.48 \pm 0.07^{\mathrm{b}}$ & $3.70 \pm 0.11^{c}$ & $5.03 \pm 0.12^{\mathrm{a}}$ & $3.48 \pm 0.08^{b, *}$ & $5.03 \pm 0.11^{\mathrm{a}, *}$ \\
\hline Mcp1 & $10.5 \pm 0.32^{\mathrm{a}}$ & $4.98 \pm 0.15^{b}$ & $7.42 \pm 0.22^{c}$ & $10.1 \pm 0.24^{\mathrm{a}}$ & $6.99 \pm 0.16^{\mathrm{b}, *}$ & $10.1 \pm 0.21 \mathrm{a}, *$ \\
\hline $\operatorname{Tnf} \alpha$ & $1.07 \pm 0.03$ & $1.01 \pm 0.03$ & $0.99 \pm 0.03$ & $1.03 \pm 0.02$ & $1.03 \pm 0.03$ & $1.00 \pm 0.03$ \\
\hline \multicolumn{7}{|c|}{ Anti-inflammatory adipokines } \\
\hline Adiponectin & $0.56 \pm 0.02^{a}$ & $0.91 \pm 0.02^{b}$ & $0.66 \pm 0.02^{c}$ & $0.58 \pm 0.02$ & $0.60 \pm 0.02 *$ & $0.57 \pm 0.02 *$ \\
\hline Il10 & $0.72 \pm 0.02$ & $0.73 \pm 0.03$ & $0.69 \pm 0.02$ & $0.70 \pm 0.03$ & $0.74 \pm 0.03$ & $0.72 \pm 0.03$ \\
\hline \multicolumn{7}{|l|}{ Angiogenic factors } \\
\hline Vegfa & $3.25 \pm 0.16^{\mathrm{a}}$ & $5.30 \pm 0.26^{b}$ & $3.97 \pm 0.16^{c}$ & $3.33 \pm 0.12^{\mathrm{a}}$ & $4.15 \pm 0.11^{b, *}$ & $3.28 \pm 0.16^{\mathrm{a}, *}$ \\
\hline Angptl4 & $2.35 \pm 0.11^{\mathrm{a}}$ & $4.89 \pm 0.13^{b}$ & $2.30 \pm 0.03^{a}$ & $2.38 \pm 0.07^{\mathrm{a}}$ & $3.84 \pm 0.07^{\mathrm{b}, *}$ & $2.28 \pm 0.06^{\mathrm{a}}$ \\
\hline Leptin & $3.60 \pm 0.18^{a}$ & $2.71 \pm 0.13^{b}$ & $3.03 \pm 0.07^{c}$ & $4.14 \pm 0.10^{\mathrm{a}, *}$ & $3.63 \pm 0.15^{b, *}$ & $3.43 \pm 0.15^{b *}$ \\
\hline \multicolumn{7}{|c|}{ Transcription factors } \\
\hline Hif $1 \alpha$ & $1.07 \pm 0.03$ & $1.01 \pm 0.03$ & $1.00 \pm 0.03$ & $1.03 \pm 0.02$ & $1.04 \pm 0.03$ & $1.00 \pm 0.03$ \\
\hline $\mathrm{Nf} k b$ & $1.62 \pm 0.08^{\mathrm{a}}$ & $1.39 \pm 0.09^{b}$ & $1.61 \pm 0.06^{\mathrm{a}}$ & $1.84 \pm 0.09 *$ & $1.69 \pm 0.07 *$ & $1.84 \pm 0.10$ * \\
\hline Ppar $\gamma$ & $0.60 \pm 0.03^{\mathrm{a}}$ & $0.86 \pm 0.03^{b}$ & $0.63 \pm 0.03^{a}$ & $0.64 \pm 0.04$ & $0.69 \pm 0.02 *$ & $0.63 \pm 0.02$ \\
\hline
\end{tabular}

${ }^{1}$ Values are means \pm SEM; $n=9 /$ culture condition. Data were normalized to Rplp0 mRNA expression and are presented as fold-changes relative to unstimulated adipocytes. Data were analyzed by two-way ANOVA. Means without a common letter differ within cultures treated \pm BADGE, $p<0.05$. ${ }^{*}$ Different from - BADGE, $p<0.05$. 
3.3. PT but not PZ Modulates Adipokine mRNA Expression in LPS $+\mathrm{CoCl}_{2}$-Stimulated Adipocytes, in Part by a PPAR- $\gamma$-Dependent Mechanism

To determine the effects of PT and PZ in modulating the adipocyte response to a combined inflammatory and hypoxic microenvironment which best represents obese AT, PT- and PZ-treated adipocytes were co-stimulated for $24 \mathrm{~h}$ with a physiological dose of LPS and $\mathrm{CoCl}_{2}$. In general, compared to separate LPS- and $\mathrm{CoCl}_{2}$-stimulated cultures, combined LPS $+\mathrm{CoCl}_{2}$ stimulation decreased the adipocyte angiogenic response and increased the inflammatory response $(p<0.05$; Tables 1-3), thus confirming this model as best representative of the obese AT adipocyte phenotype [1]. Importantly, PPAR- $\gamma$ antagonism with BADGE did not affect LPS $+\mathrm{CoCl}_{2}$-stimulated adipocyte mRNA expression (Table 3 ) or secreted adipokine levels ( $p>0.05$; Figures $1-3$ ). Within LPS $+\mathrm{CoCl}_{2}$-stimulated cultures and compared to LPS $+\mathrm{CoCl}_{2}$ stimulation alone, PT reduced mRNA expression of leptin, Il1 $\beta$, Il6, Mcp1, Tnf $\alpha$, Hif1 $\alpha$, and Nfkb, and increased Vegfa, Angptl4, adiponectin, and Ppar $\gamma(p<0.05$; Table 3), with no effect on Il10 ( $p>0.05$; Table 3). Meanwhile, PZ only increased Vegfa mRNA expression, and less potently so than PT ( $p<0.05$; Table 3$)$. Consistent with this data, PT decreased secreted IL-6 (Figure 1), MCP-1, MCP-3, MIP-1 $\alpha$ (Figure 2), and leptin (Figure 3), and increased VEGF-A (Figure 3) and adiponectin levels ( $p<0.05$; Figure 1), but did not affect TNF- $\alpha$ (Figure 1$)$ or MIP-1 $\beta(p>0.05$; Figure 2). In contrast, PZ did not affect the secreted levels of any adipokines compared to LPS + $\mathrm{CoCl}_{2}$-stimulation alone ( $p>0.05$; Figures 1-3). PPAR- $\gamma$ inhibition with BADGE partially reversed the angiogenic and anti-inflammatory effects of PT (Table 3) with the exception of adiponectin and Ppar $\gamma$ mRNA expression and secreted adiponectin and leptin, wherein BADGE totally reversed the effects of PT on adiponectin ( $p<0.05$; Table 3; Figure 1) and had no effect on Ppar $\gamma$ mRNA expression (Table 3) or secreted leptin ( $p>0.05$; Figure 3). Further, BADGE totally reversed the effect of PZ on Vegfa mRNA expression $(p<0.05$; Table 3$)$. Finally, the secreted levels of IL-1 $\beta$ and Angptl4 were undetectable in LPS $+\mathrm{CoCl}_{2}$-stimulated cultures. Collectively, these data support the anti-inflammatory and angiogenic effects of PT as well as its superior effectiveness compared to PZ in adipocytes under combined inflammatory and hypoxic conditions representative of the obese AT microenvironment. These data also confirm the role of PPAR- $\gamma$ in mediating these effects, as well as suggest an additional PPAR- $\gamma$-independent mechanism of PT action.

Table 3. mRNA expression in LPS $+\mathrm{CoCl}_{2}$-stimulated adipocytes treated with PT or PZ, with and without BADGE ${ }^{1}$.

\begin{tabular}{|c|c|c|c|c|c|c|}
\hline \multirow{2}{*}{ Gene } & No Flavonols & PT & $\mathbf{P Z}$ & No Flavonols & PT & $\mathbf{P Z}$ \\
\hline & \multicolumn{3}{|c|}{-BADGE } & \multicolumn{3}{|c|}{ +BADGE } \\
\hline \multicolumn{7}{|c|}{ Inflammatory adipokines } \\
\hline $\mathrm{Il} 1 \beta$ & $9.04 \pm 0.23^{a}$ & $4.51 \pm 0.12^{b}$ & $8.81 \pm 0.17^{\mathrm{a}}$ & $8.97 \pm 0.19^{a}$ & $6.41 \pm 0.11^{\mathrm{b}, *}$ & $8.85 \pm 0.13^{a}$ \\
\hline $\mathrm{I} 16$ & $9.07 \pm 0.26^{\mathrm{a}}$ & $4.52 \pm 0.12^{b}$ & $8.84 \pm 0.17^{\mathrm{a}}$ & $9.00 \pm 0.19^{a}$ & $7.91 \pm 0.14^{\mathrm{b}, *}$ & $8.88 \pm 0.13^{a}$ \\
\hline Mcp1 & $22.8 \pm 0.50^{\mathrm{a}}$ & $11.2 \pm 0.31^{b}$ & $21.9 \pm 0.43^{a}$ & $22.2 \pm 0.5^{\mathrm{a}}$ & $18.4 \pm 0.33^{\mathrm{b}, *}$ & $22.0 \pm 0.32^{\mathrm{a}}$ \\
\hline $\operatorname{Tnf} \alpha$ & $2.45 \pm 0.07^{\mathrm{a}}$ & $1.61 \pm 0.04^{b}$ & $2.42 \pm 0.06^{\mathrm{a}}$ & $2.40 \pm 0.06^{\mathrm{a}}$ & $2.08 \pm 0.06^{b, *}$ & $2.48 \pm 0.06^{\mathrm{a}}$ \\
\hline \multicolumn{7}{|c|}{ Anti-inflammatory adipokines } \\
\hline Adiponectin & $0.59 \pm 0.02^{\mathrm{a}}$ & $0.78 \pm 0.02^{b}$ & $0.55 \pm 0.03^{a}$ & $0.59 \pm 0.02$ & $0.57 \pm 0.03 *$ & $0.56 \pm 0.02$ \\
\hline Il10 & $0.70 \pm 0.02$ & $0.73 \pm 0.01$ & $0.70 \pm 0.03$ & $0.72 \pm 0.01$ & $0.71 \pm 0.02$ & $0.73 \pm 0.03$ \\
\hline \multicolumn{7}{|l|}{ Angiogenic factors } \\
\hline Vegfa & $1.69 \pm 0.08^{\mathrm{a}}$ & $2.39 \pm 0.14^{b}$ & $2.08 \pm 0.08^{c}$ & $1.62 \pm 0.08^{a}$ & $1.90 \pm 0.08^{b, *}$ & $1.61 \pm 0.04^{\mathrm{a}, *}$ \\
\hline Angptl4 & $1.92 \pm 0.09^{\mathrm{a}}$ & $3.41 \pm 0.21^{b}$ & $1.89 \pm 0.06^{\mathrm{a}}$ & $1.84 \pm 0.09^{a}$ & $2.90 \pm 0.08^{b, *}$ & $1.87 \pm 0.06^{\mathrm{a}}$ \\
\hline Leptin & $7.14 \pm 0.19^{a}$ & $4.13 \pm 0.10^{b}$ & $7.10 \pm 0.14^{\mathrm{a}}$ & $7.19 \pm 0.11^{\mathrm{a}}$ & $5.10 \pm 0.16^{b, *}$ & $7.05 \pm 0.11^{\mathrm{a}}$ \\
\hline \multicolumn{7}{|c|}{ Transcription factors } \\
\hline Hif1 $\alpha$ & $2.88 \pm 0.08^{a}$ & $1.90 \pm 0.05^{b}$ & $2.86 \pm 0.07^{a}$ & $2.83 \pm 0.07^{a}$ & $2.45 \pm 0.07^{\mathrm{b}, *}$ & $2.92 \pm 0.08^{a}$ \\
\hline$N f_{k b}$ & $4.13 \pm 0.12^{\mathrm{a}}$ & $2.56 \pm 0.13^{b}$ & $4.08 \pm 0.26^{\mathrm{a}}$ & $4.17 \pm 0.08^{a}$ & $3.67 \pm 0.11^{b, *}$ & $4.15 \pm 0.10^{\mathrm{a}}$ \\
\hline Ppar $\gamma$ & $0.50 \pm 0.04^{\mathrm{a}}$ & $0.68 \pm 0.02^{b}$ & $0.49 \pm 0.01^{\mathrm{a}}$ & $0.45 \pm 0.03^{a}$ & $0.68 \pm 0.05^{b}$ & $0.48 \pm 0.04^{\mathrm{a}}$ \\
\hline
\end{tabular}




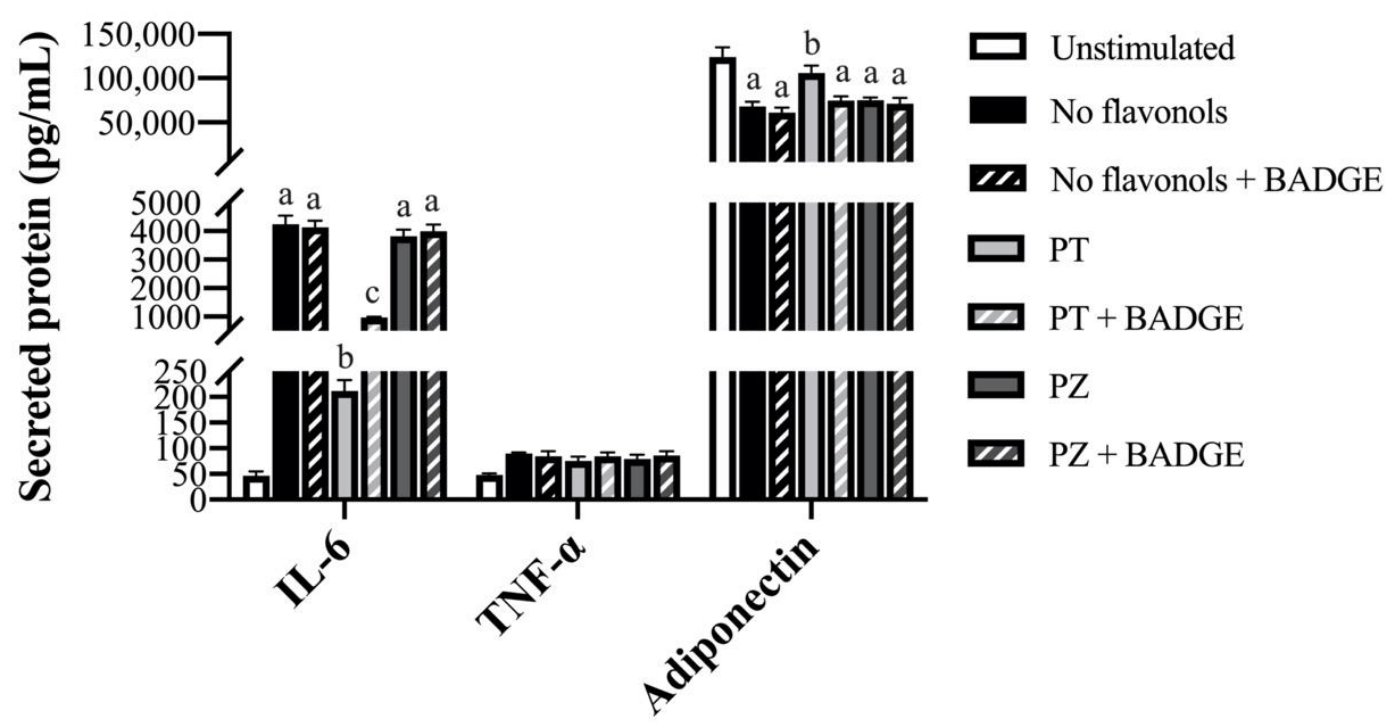

Figure 1. Secreted protein levels of inflammatory (interleukin (IL)-6 and tumor necrosis factor (TNF)- $\alpha$ ) and anti-inflammatory (adiponectin) adipokines in lipopolysaccharide (LPS) + cobalt chloride $\left(\mathrm{CoCl}_{2}\right)$-stimulated adipocytes co-treated with phloretin (PT) or phlorizin (PZ), with or without bisphenol A diglycidyl ether (BADGE). Values are means \pm standard error of the mean (SEM); $n=9$ /treatment. Data were analyzed by two-way ANOVA and means without a common letter differ within cultures treated \pm BADGE, $p<0.05$.

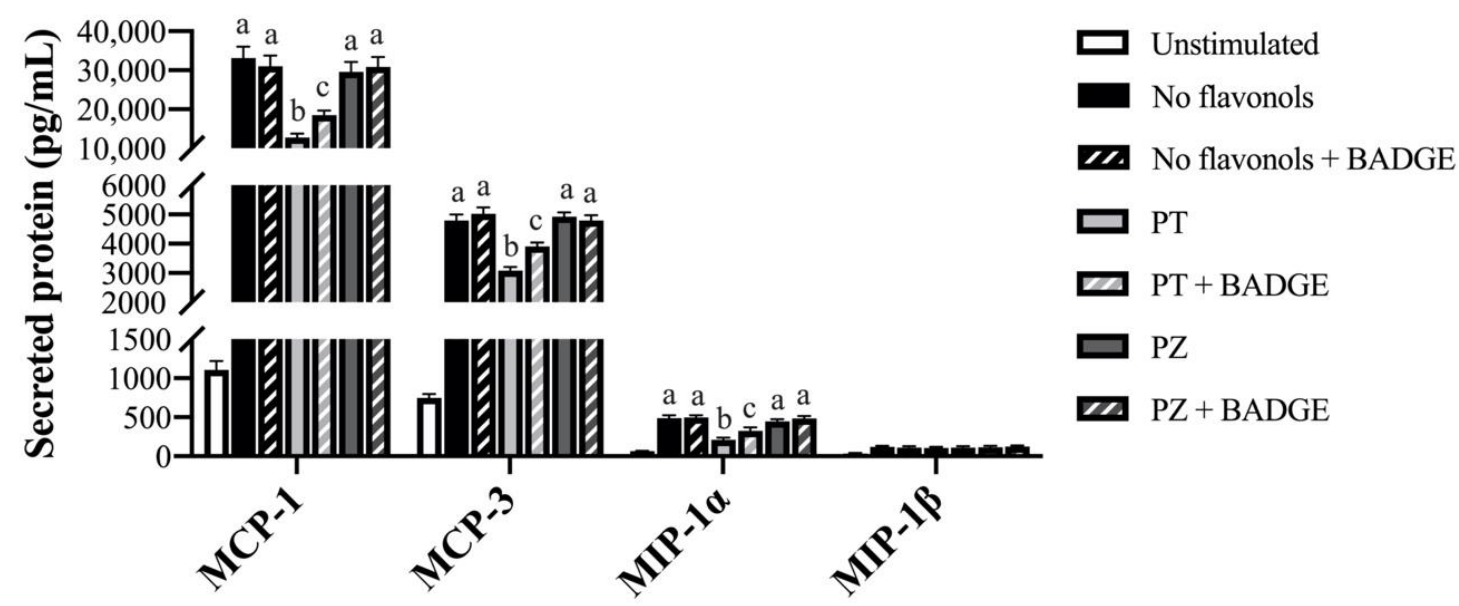

Figure 2. Secreted protein levels of macrophage chemotactic adipokines (monocyte chemoattractant protein (MCP)-1, MCP-3, macrophage inflammatory protein (MIP)-1 $\alpha$ and MIP-1 $\beta$ ) in LPS + $\mathrm{CoCl}_{2}$-stimulated adipocytes co-treated with PT or PZ, with or without BADGE. Values are means \pm SEM; $n=9$ /treatment. Data were analyzed by two-way ANOVA and means without a common letter differ within cultures treated \pm BADGE, $p<0.05$. 


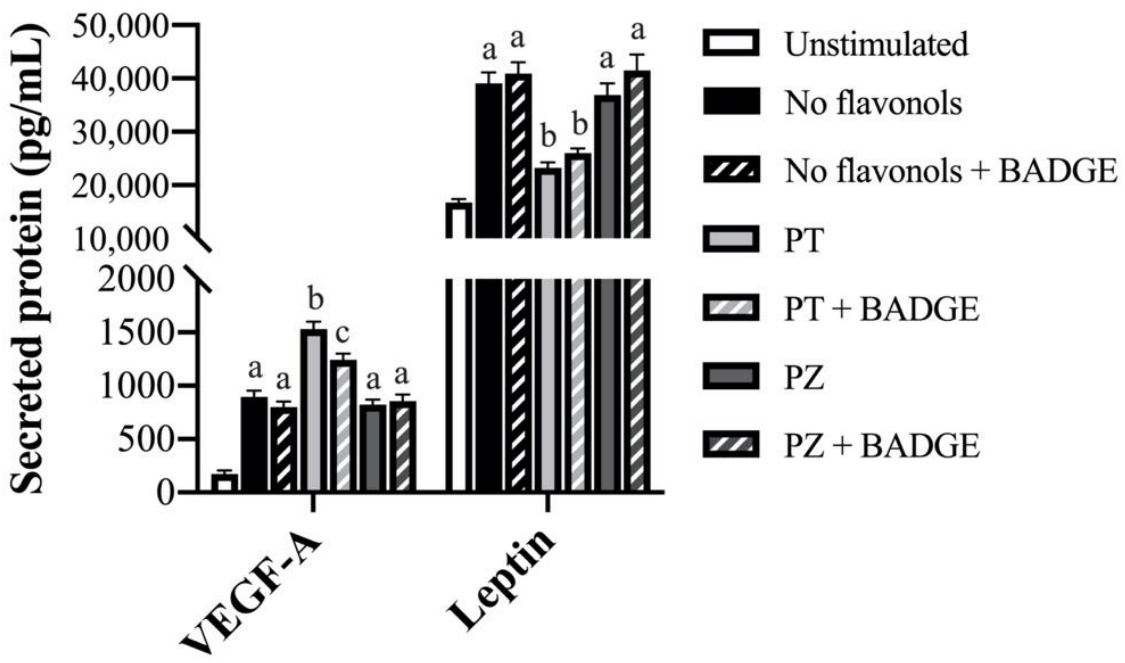

Figure 3. Secreted protein levels of angiogenic factors (vascular endothelial growth factor (VEGF)-A and leptin) in LPS $+\mathrm{CoCl}_{2}$-stimulated adipocytes co-treated with PT or PZ, with or without BADGE. Values are means \pm SEM; $n=9$ /treatment. Data were analyzed by two-way ANOVA and means without a common letter differ within cultures treated \pm BADGE, $p<0.05$.

3.4. PT but not PZ reduced ROS Accumulation and NF- $\mathrm{kB}$ Activation in LPS $+\mathrm{CoCl}_{2}$-Stimulated Adipocytes, in Part by a PPAR- $\gamma$-Dependent Mechanism

NF- $\mathrm{kB}$ p65 activation and ROS accumulation were measured in LPS $+\mathrm{CoCl}_{2}$-stimulated cultures to determine additional mechanisms through which PT exerts its angiogenic and anti-inflammatory effects. As expected, LPS $+\mathrm{CoCl}_{2}$ stimulation increased the adipocyte ratio of phosphorylated (i.e., activated) to total NF-kB p65 (Ser536) $(p<0.05$; Figure 4$)$, and increased ROS accumulation compared to the unstimulated condition ( $p<0.05$; Figure 5). Compared to LPS $+\mathrm{CoCl}_{2}$-stimulated adipocytes, PT reduced the ratio of phosphorylated to total NF- $\mathrm{KB}$ p65 ( $p<0.05$; Figure 4); an effect that was partially reversed by BADGE ( $p<0.05$; Figure 4$)$. Likewise, PT reduced ROS accumulation $(p<0.05$; Figure 5$)$ and PPAR- $\gamma$ antagonism with BADGE had no relative effect $(p>0.05$; Figure 5$)$. In contrast, PZ did not affect the adipocyte ratio of phosphorylated to total NF- $\mathrm{kB}$ p65 (Figure 4) or ROS accumulation (Figure 5) compared to the LPS $+\mathrm{CoCl}_{2}$-stimulated condition $(p>0.05)$. These data provide mechanistic insight into the anti-inflammatory and angiogenic effects of PT relative to PZ in adipocytes and further support an additional PPAR- $\gamma$-independent mechanism of action for PT in a combined inflammatory and hypoxic microenvironment representative of obese AT.

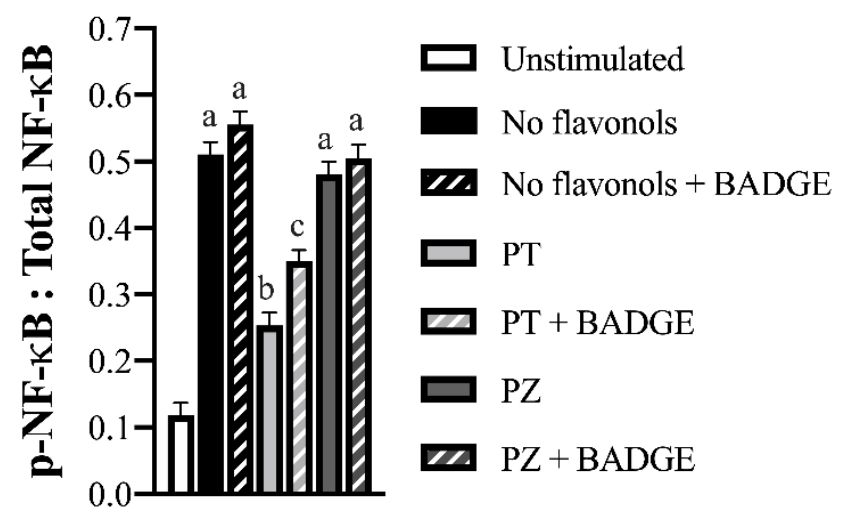

Figure 4. Activated (i.e., phosphorylated) nuclear factor kappa-light-chain-enhancer of activated B cells (NF-kB p65, Ser536): total NF- $\mathrm{BB}$ p65 in LPS $+\mathrm{CoCl}_{2}$-stimulated adipocytes co-treated with PT or PZ, with or without BADGE. Values are means \pm SEM; $n=9 /$ treatment. Data were analyzed by two-way ANOVA and means without a common letter differ within cultures treated \pm BADGE, $p<0.05$. 


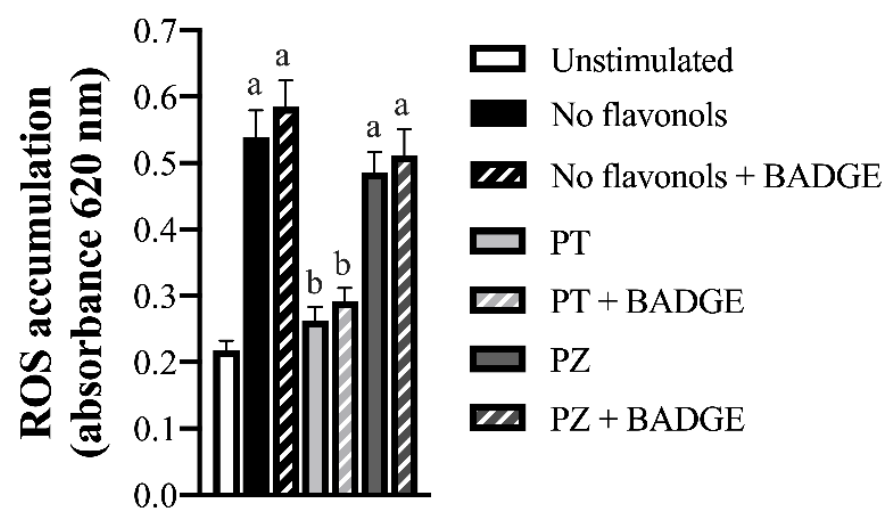

Figure 5. Cellular reactive oxygen species (ROS) accumulation in LPS $+\mathrm{CoCl}_{2}$-stimulated adipocytes co-treated with PT or PZ, with or without BADGE. Values are means \pm SEM; $n=9$ /treatment. Data were analyzed by two-way ANOVA and means without a common letter differ within cultures treated \pm BADGE, $p<0.05$.

3.5. PT but not PZ Modulates Cellular Regulators of Apoptosis in LPS $+\mathrm{CoCl}_{2}$-Stimulated Adipocytes, in Part by a PPAR- $\gamma$-Dependent Mechanism

Cellular regulators of apoptosis of the BCL-2 family were measured in LPS $+\mathrm{CoCl}_{2}$-stimulated cultures to determine the effects of PT and PZ on markers of cell survival in an inflammatory and hypoxic microenvironment reflective of the obese AT milieu. As expected, in general, $\mathrm{LPS}+\mathrm{CoCl}_{2}$ stimulation increased cellular apoptotic and decreased anti-apoptotic protein levels compared to the unstimulated condition ( $p<0.05$; Figure 6 ). Interestingly, PPAR- $\gamma$ antagonism with BADGE further increased apoptotic BAD levels and further decreased anti-apoptotic BCL-2/BAX and BCL-XL levels in LPS $+\mathrm{CoCl}_{2}$ stimulated-adipocytes $(p<0.05$; Figure 6$)$, with no effect on apoptotic BIM $(p>0.05$; Figure 6). Consistent with the anti-inflammatory and angiogenic effects of PT in the LPS $+\mathrm{CoCl}_{2}$-stimulated condition, PT reduced BAD and BIM, and increased BCL-2/BAX and BCL-XL $(p<0.05$; Figure 6$)$. The anti-apoptotic effects of PT on BAD, BCL-2/BAX, and BCL-XL were partially reversed by BADGE ( $p<0.05$; Figure 6$)$, whereas BADGE had no effect on BIM $(p>0.05$; Figure 6$)$. Finally, PZ did not affect cellular levels of regulators of apoptosis compared to LPS $+\mathrm{CoCl}_{2}$-stimulated adipocytes $(p>0.05$; Figure 6$)$, and anti-apoptotic MCL-1 was only minimally detected in LPS + $\mathrm{CoCl}_{2}$-stimulated cultures and was unaffected by treatment $(p>0.05$; Figure 6$)$. Consistent with its anti-inflammatory and angiogenic effects, these data suggest PT promotes an anti-apoptotic protein profile in adipocytes exposed to combined inflammation and hypoxia, representative of the obese AT microenvironment. 


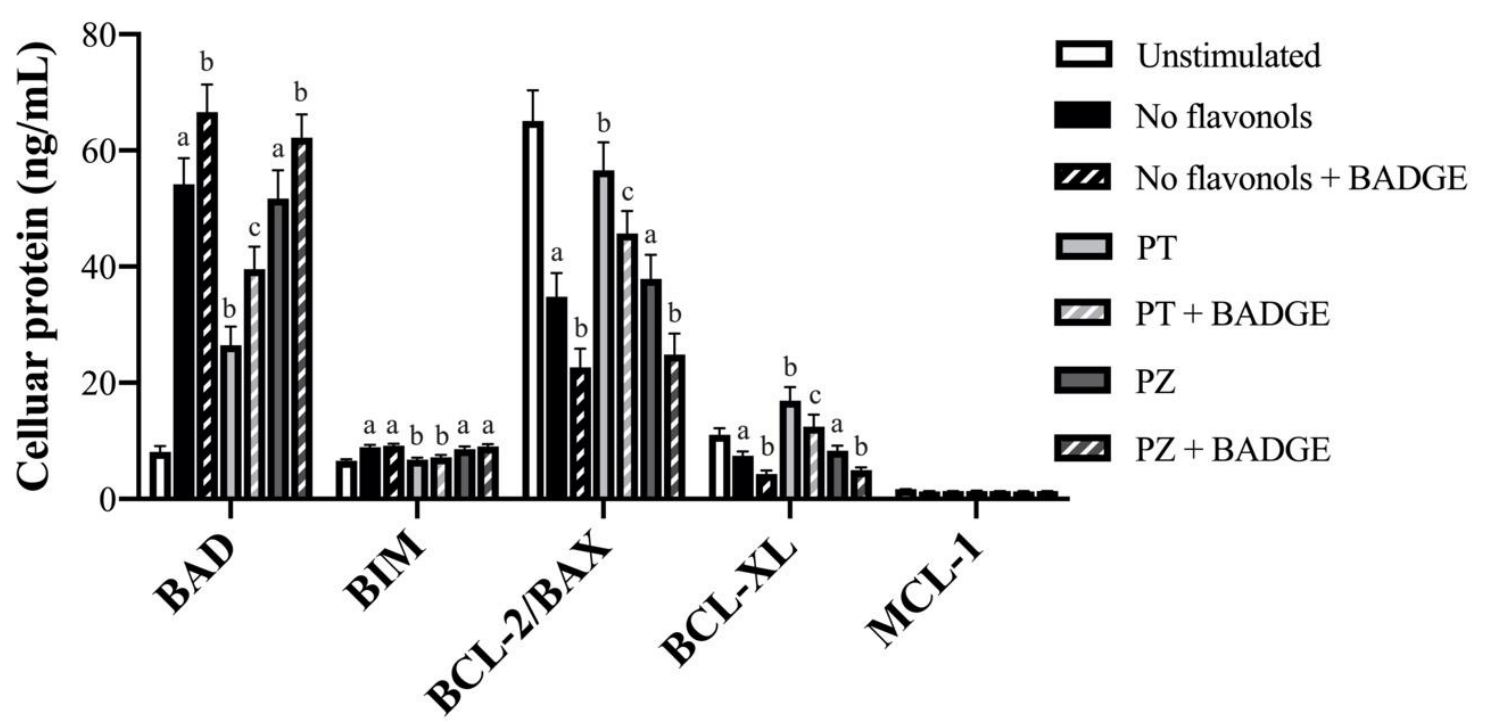

Figure 6. Cellular protein levels of regulators of apoptosis of the B-cell lymphoma 2 (BCL-2) protein family (BCL-2-associated agonist of cell death (BAD), BCL-2-like protein 11 (BIM), BCL-2/BCL-2-like protein 4 (BAX), B-cell lymphoma-extra-large (BCL-XL)) in LPS $+\mathrm{CoCl}_{2}$-stimulated adipocytes co-treated with PT or PZ, with or without BADGE. Values are means \pm SEM; $n=9 /$ treatment. Data were analyzed using a two-way ANOVA and means without a common letter differ within cultures treated \pm BADGE, $p<0.05$.

3.6. PT and PZ Treatment of LPS $+\mathrm{CoCl}_{2}$-Stimulated Adipocytes in Turn Modulate Macrophage Expression of M1 and M2 Polarization Markers

Macrophages were cultured in conditioned media collected from adipocytes stimulated with LPS $+\mathrm{CoCl}_{2}$ to determine the effects of (adipocyte treatment with) PT and PZ in modulating mRNA expression of markers of macrophage polarization in response to adipocyte inflammation and hypoxia. As expected, conditioned media collected from LPS $+\mathrm{CoCl}_{2}$-stimulated adipocytes in turn increased macrophage mRNA expression of markers of M1 polarization and decreased that of M2 polarization compared to the effects of unstimulated adipocyte conditioned media on macrophages $(p<0.05$; Table 4$)$. Consistent with our secreted inflammatory (Figure 1) and macrophage chemotactic adipokine (Figure 2) data in LPS $+\mathrm{CoCl}_{2}$-stimulated adipocytes, PT (co-treatment of adipocytes) reduced macrophage mRNA expression of the M1 polarization markers $i N o s, I l 6$, and Tnf $\alpha$, and increased expression of the M2 polarization markers $\operatorname{Arg} 1, I l 10$, and $\operatorname{Tgf} \beta(p<0.05$; Table 4). Unexpectedly, despite no effects on secreted adipokines in LPS $+\mathrm{CoCl}_{2}$-stimulated adipocytes, PZ (co-treatment of adipocytes) also reduced macrophage mRNA expression of $I l 6$ and Tnf $\alpha(p<0.05$; Table 4). Interestingly, adipocyte PPAR- $\gamma$ inhibition with BADGE in turn further increased macrophage mRNA expression of $i$ Nos, Il6, and Tnf $\alpha(p<0.05$; Table 4$)$ but did not affect expression of M2 polarization markers $(p>0.05$; Table 4$)$. The effects of PT on macrophage mRNA expression of M1 and M2 polarization markers were partially reversed by BADGE $(p<0.05$; Table 4$)$ with the exception of $T f g \beta$ which was unaffected by BADGE $(p>0.05$; Table 4); whereas, in contrast, the effects of PZ on M1 polarization markers were totally reversed by BADGE $(p<0.05$; Table 4$)$. These data suggest PT and PZ modulation of the adipocyte response to combined inflammation and hypoxia in turn mitigates macrophage $\mathrm{M} 1$ polarization and promotes M2 polarization, and supports the role of PPAR- $\gamma$ in mediating PT and PZ modulation of adipocyte-macrophage interactions. 
Table 4. mRNA expression in macrophages cultured in conditioned media from $\mathrm{LPS}+\mathrm{CoCl}_{2}$-stimulated adipocytes co-treated with PT or PZ, with and without BADGE ${ }^{1}$.

\begin{tabular}{|c|c|c|c|c|c|c|}
\hline \multirow{2}{*}{ Gene } & No Flavonols & PT & PZ & No Flavonols & PT & $\mathbf{P Z}$ \\
\hline & \multicolumn{3}{|c|}{-BADGE } & \multicolumn{3}{|c|}{ +BADGE } \\
\hline \multicolumn{7}{|c|}{ M1 polarization markers } \\
\hline $\mathrm{Cd} 11 \mathrm{~b}$ & $2.89 \pm 0.05$ & $2.73 \pm 0.08$ & $2.81 \pm 0.13$ & $2.94 \pm 0.19$ & $2.93 \pm 0.12$ & $2.87 \pm 0.12$ \\
\hline Cd11c & $3.45 \pm 0.12$ & $3.41 \pm 0.13$ & $3.55 \pm 0.12$ & $3.59 \pm 0.11$ & $3.50 \pm 0.11$ & $3.59 \pm 0.10$ \\
\hline iNos & $10.1 \pm 0.27^{\mathrm{a}}$ & $6.49 \pm 0.29^{b}$ & $10.8 \pm 0.32^{\mathrm{a}}$ & $13.4 \pm 0.61^{\mathrm{a}, *}$ & $10.7 \pm 0.46^{b, *}$ & $12.8 \pm 0.39^{a, *}$ \\
\hline Il6 & $6.16 \pm 0.12^{\mathrm{a}}$ & $4.31 \pm 0.11^{b}$ & $5.60 \pm 0.08^{c}$ & $9.46 \pm 0.28^{a, *}$ & $6.53 \pm 0.20^{b, *}$ & $9.20 \pm 0.19^{a, *}$ \\
\hline $\operatorname{Tnf} \alpha$ & $9.10 \pm 0.14^{\mathrm{a}}$ & $5.42 \pm 0.11^{b}$ & $7.61 \pm 0.17^{c}$ & $14.9 \pm 0.13^{\mathrm{a}, *}$ & $9.18 \pm 0.18^{b, *}$ & $14.6 \pm 0.12^{\mathrm{a}, *}$ \\
\hline \multicolumn{7}{|c|}{ M2 polarization markers } \\
\hline $\mathrm{Cd} 206$ & $0.96 \pm 0.02$ & $1.05 \pm 0.04$ & $0.99 \pm 0.02$ & $0.98 \pm 0.02$ & $1.01 \pm 0.03$ & $1.01 \pm 0.02$ \\
\hline ‘Arg1 & $0.51 \pm 0.03^{\mathrm{a}}$ & $0.73 \pm 0.01^{b}$ & $0.57 \pm 0.03^{\mathrm{a}}$ & $0.53 \pm 0.03^{a}$ & $0.66 \pm 0.03^{b, *}$ & $0.58 \pm 0.02^{\mathrm{a}}$ \\
\hline Il10 & $0.61 \pm 0.01^{\mathrm{a}}$ & $0.91 \pm 0.02^{b}$ & $0.64 \pm 0.02^{\mathrm{a}}$ & $0.58 \pm 0.01^{\mathrm{a}}$ & $0.84 \pm 0.02^{b, *}$ & $0.61 \pm 0.01^{\mathrm{a}}$ \\
\hline $\operatorname{Tgf} \beta$ & $0.65 \pm 0.01^{\mathrm{a}}$ & $0.89 \pm 0.02^{b}$ & $0.68 \pm 0.01^{\mathrm{a}}$ & $0.69 \pm 0.01^{a}$ & $0.84 \pm 0.03^{b}$ & $0.71 \pm 0.01^{\mathrm{a}}$ \\
\hline
\end{tabular}

${ }^{1}$ Values are means \pm SEM; $n=9 /$ culture condition. Data were normalized to Rplp0 mRNA and are presented as fold-changes relative to macrophages cultured in conditioned media collected from unstimulated adipocytes. Data were analyzed by two-way ANOVA. Means without a common letter differ within cultures treated \pm BADGE, $p<0.05 .{ }^{*}$ Different from -BADGE, $p<0.05$.

\section{Discussion}

Chronic AT inflammation, as an adaptive response to adipocyte hypoxia [9], represents a pivotal target for dietary intervention to mitigate the development of obesity-associated metabolic diseases, such as T2D and CVD [8]. Using culture conditions reflective of the obese AT hypoxic and inflammatory microenvironment, we provide evidence that the apple flavonols PT and PZ reduce adipocyte inflammation and promote the production of angiogenic factors; effects which have been shown to contribute to preserving AT insulin sensitivity [35]. Importantly, the anti-inflammatory and angiogenic effects of PT were consistently more potent than PZ. Further, we showed the effects of PT and PZ were partly or totally mediated through a PPAR- $\gamma$-dependent mechanism, with reduced NF- $k B$ activation and ROS accumulation as potential additional interrelated mechanisms through which PT exerts its more potent effects. Finally, the ability of PT to promote angiogenesis and reduce ROS accumulation, a by-product of metabolic stress [6], was supported by altered levels of cellular mediators of apoptosis towards an anti-apoptotic profile. Collectively, our data provide mechanistic insight into the potential for apple-derived flavonols to attenuate critical aspects of the obese AT phenotype, and thus suggest a relatively common dietary component as a useful strategy for preventing chronic metabolic diseases.

To our knowledge, this is the first report of the effects of PT and PZ in LPS-stimulated (mature) adipocytes, and the first report under hypoxic conditions in any cell type. Nonetheless, the PT- and PZ-mediated anti-inflammatory effects observed herein are consistent with other in vitro evidence. In one report of unstimulated adipocytes, treatment with $50 \mu \mathrm{M}$ PT reduced mRNA expression of IL- 6 and MCP-3 and increased mRNA expression of both adiponectin and its receptor [24]. In another report, in TNF- $\alpha$-stimulated adipocytes, pre-treatment with 10,30 , and $100 \mu \mathrm{M}$ PT or $100 \mu \mathrm{M} \mathrm{PZ}$ reduced secreted MCP-1 and/or another immune cell chemotactic adipokine, regulated on activation, normal T-cell expressed and secreted [26]. Likewise, in LPS-stimulated macrophages, pre-treatment with 10, 30, and $100 \mu \mathrm{M}$ PT or $100 \mu \mathrm{M}$ PZ reduced secreted IL-6 and/or TNF- $\alpha$ levels [25], as did pre-treatment with 10 and $30 \mu \mathrm{g} / \mathrm{mL} \mathrm{PT}$ or PZ [36]. Notably, the high concentration of LPS (1000 $\mathrm{ng} / \mathrm{mL})$ in these works compared to the obese physiological dose $(10 \mathrm{ng} / \mathrm{mL})$ used in our cultures suggests the high anti-inflammatory potency of PT and, to a lesser extent, PZ. Further, the timing of PT and PZ treatment and inflammatory stimulation (with LPS or TNF- $\alpha$ ) differed between these studies $[25,26,36]$ and ours; it is possible that PT or PZ pre-treatment in these studies primed the adipocyte/macrophage response to the inflammatory stimuli towards an anti-inflammatory phenotype. Still, similar to the current study design, co-treatment with $45 \mu \mathrm{M}$ PT or PZ was estimated to be effective at reducing secreted TNF- $\alpha$ levels in $(500 \mathrm{ng} / \mathrm{mL})$ LPS-stimulated macrophages [37]. While 
macrophages are the primary cellular source of TNF- $\alpha$ in AT [38], its mRNA and secreted protein levels were reportedly doubled in adipocytes isolated from obese compared to lean humans [39]. Interestingly, in the current study, TNF- $\alpha$ mRNA and secreted proteins levels were only increased and influenced by PT in the LPS $+\mathrm{CoCl}_{2}$-stimulated condition, thus further supporting these aforementioned data on the anti-inflammatory potential of PT and PZ in the complex obese AT microenvironment.

The preventative effects of PT and PZ on obese AT inflammation as supported by the current and aforementioned [24-26,36] in vitro work are consistent with the limited in vivo reports [28,29]. To our knowledge, there are no in vivo comparisons of PT and PZ in the context of obesity-associated inflammation and hypoxia. However, it is conceivable that PT would be more effective, as PZ is suggested to be hydrolyzed by gut lactase PZ hydrolase, yielding the PT aglycone for absorption [31]. Indeed, a near equal plasma concentration of total PT was observed in PT- and PZ-fed rodents, whereas PZ was not detected in the plasma of either dietary group [31]. Further, in addition to the C-4' hydroxyl group which PT and PZ share, and as our results would support, PT may be a more effective PPAR- $\gamma$ agonist given its free C-2' hydroxyl group where PZ is instead glycosylated [40], and which is also suggested to participate in stabilizing ROS [41]. PT has also been shown to mitigate ROS via endogenous antioxidant pathways involving nuclear factor erythroid 2-related factor 2, superoxide dismutase, and glutathione [42]. Collectively, these kinetic and structural differences between PT and PZ may explain the PPAR- $\gamma$-dependent and -independent inhibitory effects of PT on NF- $\mathrm{kB}$ activation, ROS accumulation, and ensuing adipokine regulation, whereas PZ was relatively inert in the LPS + $\mathrm{CoCl}_{2}$-stimulated condition.

Another novel aspect of the current study is the addition of $\mathrm{CoCl}_{2}$ to adipocyte cultures alone and in combination with LPS to measure the effect of PT and PZ in mediating the hypoxic response. In the obese AT condition of sustained hypoxia, HIF-1 contributes to AT fibrosis instead of angiogenesis, thus restricting adipocyte (and AT) expansion and lipid storage, and inducing inflammation [43] and eventual apoptosis [15]. In the current study, PT increased angiogenic adipokine expression and/or secreted levels, whereas PZ was relatively inert. Interestingly though, PT reduced leptin mRNA expression in all culture conditions, as well as secreted leptin in the LPS $+\mathrm{CoCl}_{2}$-stimulated condition, perhaps to mitigate the potential inflammatory effects of leptin despite its angiogenic effects [44], but further study is required. Nonetheless, PT also modulated cellular levels of apoptotic proteins towards an anti-apoptotic profile. Although these data were unsupported by any differences in cell viability (and we did not measure apoptosis directly), these PT-mediated effects may represent an early, protective response to sustained hypoxia in obese AT, though further study is required.

Hypoxic areas of AT are classically co-localized with macrophages, indicating an association between hypoxia and immune cell recruitment and infiltration [45]. Further, under hypoxic conditions, macrophages were observed to polarize to the M1 inflammatory phenotype [46], and were the major source of inflammatory adipokines amongst all AT immune cells [45], whereas anti-inflammatory M2 but not M1 macrophages were reported to contribute to angiogenesis in vivo [47]. In the current study, PT co-treatment of LPS $+\mathrm{CoCl}_{2}$-stimulated adipocytes in turn modulated macrophage mRNA expression of polarization markers towards the M2 phenotype, most of which was partially dependent on adipocyte PPAR- $\gamma$ activity. Unexpectedly, despite no effects on secreted adipokines in LPS + $\mathrm{CoCl}_{2}$-stimulated adipocytes, PZ also reduced macrophage IL- 6 and TNF- $\alpha$ mRNA expression, which was totally dependent on adipocyte PPAR- $\gamma$ activity. In addition to reducing inflammatory adipokine production and increasing adiponectin, it is conceivable that PT and PZ activation of adipocyte PPAR- $\gamma$ also interfered with LPS- and hypoxia-induced lipolysis and instead promoted lipogenesis [48]. Indeed, adipocyte-derived fatty acids have been shown to promote macrophage polarization towards the M1 phenotype [49]. However, further study is required to understand the role of PT and PZ in mediating adipocyte lipogenesis and paracrine interactions with macrophages as controversy exists [26].

Despite our efforts to design cell culture models that are physiologically relevant to obese AT in vivo, it must be acknowledged that dietary flavonols are rarely consumed in isolation, but rather as part of complex food matrices containing fiber, phytosterols, vitamins, minerals, and other molecules 
that may synergize or antagonize them directly or through secondary signaling pathways. Further, while $100 \mu \mathrm{M}$ PT (as utilized in the current study) is reportedly representative of the maximum plasma concentration of total PT that was achieved in PT- and PZ-supplemented rats, the majority of plasma PT was conjugated in the form of glucuronides and sulfates [31] which may have health effects separate from PT. Similarly, our timing of LPS and $\mathrm{CoCl}_{2}$ stimulation may not adequately reflect the pathology of expanding AT in that AT hypoxia is suggested to precede inflammation in obesity [35]. Finally, the effects of $\mathrm{CoCl}_{2}$ on some inflammatory and angiogenic adipokine mRNA expression have been shown to peak at $8-16 \mathrm{~h}$ of stimulation, but to be lost at $24 \mathrm{~h}$ as employed in the current study; whereas the effects of ambient hypoxia peaked at $24 \mathrm{~h}$ [12].

\section{Conclusions}

This study provides evidence for the anti-inflammatory and angiogenic effects of the apple flavonol PT in models designed to mimic the obese AT microenvironment, including inflammation and hypoxia, which are interrelated conditions that drive AT metabolic dysfunction and contribute to T2D and CVD [8,9]. We showed PT consistently mitigates inflammatory adipokines whilst increasing adiponectin and angiogenic adipokine production in LPS-, $\mathrm{CoCl}_{2^{-}}$, and LPS $+\mathrm{CoCl}_{2}$-stimulated adipocytes. This data was complimented by blunted adipocyte NF- $\mathrm{kB}$ activation and ROS accumulation, and alterations in the expression of apoptotic mediators towards an anti-apoptotic profile. In turn, LPS $+\mathrm{CoCl}_{2}$-stimulated adipocyte co-treatment with PT mitigated macrophage expression of M1 polarization markers and promoted expression of M2 polarization markers. Finally, we confirmed the effects of PT are partially dependent on PPAR- $\gamma$ activity and confirmed the superior effectiveness of PT compared to PZ towards these endpoints. Collectively, our findings provide mechanistic support for the consumption of apples, a relatively common dietary component, in the prevention of obesity-associated disease.

Supplementary Materials: The following are available online at http:/www.mdpi.com/2072-6643/12/5/1386/s1, Table S1: Primer sequences.

Author Contributions: Conceptualization, D.M.L. and L.E.R.; Methodology, D.M.L. and M.E.K.; Investigation, D.M.L. and M.E.K.; Writing-Original draft preparation, D.M.L.; Writing-Review and editing, D.M.L., M.E.K, A.J.W, and L.E.R.; Supervision, A.J.W. and L.E.R.; Funding acquisition, L.E.R. All authors have read and agreed to the published version of the manuscript.

Funding: This work was supported by the Natural Sciences and Engineering Research Council of Canada (NSERC). D.M.L. was supported by an NSERC Canada Graduate Scholarship.

Conflicts of Interest: The authors declare no conflict of interest. The funders had no role in the design of the study; in the collection, analyses, or interpretation of data; in the writing of the manuscript, or in the decision to publish the results.

\section{References}

1. Hammarstedt, A.; Gogg, S.; Hedjazifar, S.; Nerstedt, A.; Smith, U. Impaired Adipogenesis and Dysfunctional Adipose Tissue in Human Hypertrophic Obesity. Physiol. Rev. 2018, 98, 1911-1941. [CrossRef] [PubMed]

2. Meijer, K.; de Vries, M.; Al-Lahham, S.; Bruinenberg, M.; Weening, D.; Dijkstra, M.; Kloosterhuis, N.; van der Leij, R.J.; van der Want, H.; Kroesen, B.J.; et al. Human primary adipocytes exhibit immune cell function; adipocytes prime inflammation independent of macrophages. PLoS ONE 2011, 6, e17154. [CrossRef] [PubMed]

3. Shi, H.; Kokoeva, M.V.; Inouye, K.; Tzameli, I.; Yin, H.; Flier, J.S. TLR4 links innate immunity and fatty acid-induced insulin resistance. J. Clin. Investig. 2006, 116, 3015-3025. [CrossRef] [PubMed]

4. Cani, P.D.; Amar, J.; Iglesias, M.A.; Poggi, M.; Knauf, C.; Bastelica, D.; Neyrinck, A.M.; Fava, F.; Tuohy, K.M.; Chabo, C.; et al. Metabolic endotoxemia initiates obesity and insulin resistance. Diabetes 2007, 56, 1761-1772. [CrossRef] [PubMed]

5. Ozcan, U.; Cao, Q.; Yilmaz, E.; Lee, A.H.; Iwakoshi, N.N.; Ozdelen, E.; Tuncman, G.; Görgün, C.; Glimcher, L.H.; Hotamisligil, G.S. Endoplasmic reticulum stress links obesity, insulin action, and type 2 diabetes. Science 2004, 306, 457-461. [CrossRef] [PubMed] 
6. Furukawa, S.; Fujita, T.; Shimabukuro, M.; Iwaki, M.; Yamada, Y.; Nakajima, Y.; Nakayama, O.; Makishima, M.; Matsuda, M.; Shimomura, I. Increased oxidative stress in obesity and its impact on metabolic syndrome. J. Clin. Investig. 2004, 114, 175-176. [CrossRef]

7. Lumeng, C.N.; Bodzin, J.L.; Saltiel, A.R. Obesity induces a phenotypic switch in adipose tissue macrophage polarization. J. Clin. Investig. 2007, 117, 175-184. [CrossRef]

8. Hotamisligil, G.S. Inflammation and metabolic disorders. Nature 2006, 444, 860-867. [CrossRef]

9. Trayhurn, P. Hypoxia and adipose tissue function and dysfunction in obesity. Physiol. Rev. 2013, 93, 1-21. [CrossRef]

10. Skurk, T.; Alberti-Huber, C.; Herder, C.; Hauner, H. Relationship between adipocyte size and adipokine expression and secretion. J. Clin. Endocrinol. Metab. 2007, 92, 1023-1033. [CrossRef]

11. Lolmède, K.; de Saint Front, V.D.; Galitzky, J.; Lafontan, M.; Bouloumié, A. Effects of hypoxia on the expression of proangiogenic factors in differentiated 3T3-F442A adipocytes. Int. J. Obes. Relat. Metab. Disord. 2003, 27, 1187-1195. [CrossRef] [PubMed]

12. Wang, B.; Wood, I.S.; Trayhurn, P. Dysregulation of the expression and secretion of inflammation-related adipokines by hypoxia in human adipocytes. Pflugers Arch. 2007, 455, 479-492. [CrossRef] [PubMed]

13. Ye, J.; Gao, Z.; Yin, J.; He, Q. Hypoxia is a potential risk factor for chronic inflammation and adiponectin reduction in adipose tissue of ob/ob and dietary obese mice. Am. J. Physiol. Endocrinol. Metab. 2007, 293, E1118-E1128. [CrossRef] [PubMed]

14. Pasarica, M.; Sereda, O.R.; Redman, L.M.; Albarado, D.C.; Hymel, D.T.; Roan, L.E.; Rood, J.C.; Burk, D.H.; Smith, S.R. Reduced adipose tissue oxygenation in human obesity: Evidence for rarefaction, macrophage chemotaxis, and inflammation without an angiogenic response. Diabetes 2009, 58, 718-725. [CrossRef]

15. Giordano, A.; Murano, I.; Mondini, E.; Perugini, J.; Smorlesi, A.; Severi, I.; Barazzoni, R.; Scherer, P.E.; Cinti, S. Obese adipocytes show ultrastructural features of stressed cells and die of pyroptosis. J. Lipid Res. 2013, 54, 2423-2436. [CrossRef]

16. Cinti, S.; Mitchell, G.; Barbatelli, G.; Murano, I.; Ceresi, E.; Faloia, E.; Wang, S.; Fortier, M.; Greenberg, A.S.; Obin, M.S. Adipocyte death defines macrophage localization and function in adipose tissue of obese mice and humans. J. Lipid Res. 2005, 46, 2347-2355. [CrossRef]

17. Lee, B.C.; Lee, J. Cellular and molecular players in adipose tissue inflammation in the development of obesity-induced insulin resistance. Biochim. Biophys. Acta 2014, 1842, 446-462. [CrossRef]

18. Arts, I.C.; Hollman, P.C. Polyphenols and disease risk in epidemiologic studies. Am. J. Clin. Nutr. 2005, 81, 317S-325S. [CrossRef]

19. Scalbert, A.; Williamson, G. Dietary intake and bioavailability of polyphenols. J. Nutr. 2000, 130, 2073S-2085S. [CrossRef] [PubMed]

20. Hyson, D.A. A comprehensive review of apples and apple components and their relationship to human health. Adv. Nutr. 2011, 2, 408-420. [CrossRef]

21. Vrhovsek, U.; Rigo, A.; Tonon, D.; Mattivi, F. Quantitation of polyphenols in different apple varieties. J. Agric. Food Chem. 2004, 52, 6532-6538. [CrossRef] [PubMed]

22. Hassan, M.; Yazidi, C.E.; Landrier, J.F.; Lairon, D.; Margotat, A.; Amiot, M.J. Phloretin enhances adipocyte differentiation and adiponectin expression in 3T3-L1 cells. Biochem. Biophys. Res. Commun. 2007, 361, 208-213. [CrossRef] [PubMed]

23. Gealekman, O.; Burkart, A.; Chouinard, M.; Nicoloro, S.M.; Straubhaar, J.; Corvera, S. Enhanced angiogenesis in obesity and in response to PPARgamma activators through adipocyte VEGF and ANGPTL4 production. Am. J. Physiol. Endocrinol. Metab. 2008, 295, E1056-E1064. [CrossRef] [PubMed]

24. Hassan, M.; Yazidi, C.E.; Malezet-Desmoulins, C.; Amiot, M.J.; Margotat, A. Gene expression profiling of 3T3-L1 adipocytes exposed to phloretin. J. Nutr. Biochem. 2010, 21, 645-652. [CrossRef] [PubMed]

25. Chang, W.T.; Huang, W.C.; Liou, C.J. Evaluation of the anti-inflammatory effects of phloretin and phlorizin in lipopolysaccharide-stimulated mouse macrophages. Food Chem. 2012, 134, 972-979. [CrossRef] [PubMed]

26. Huang, W.C.; Chang, W.T.; Wu, S.J.; Xu, P.Y.; Ting, N.C.; Liou, C.J. Phloretin and phlorizin promote lipolysis and inhibit inflammation in mouse 3T3-L1 cells and in macrophage-adipocyte co-cultures. Mol. Nutr. Food Res. 2013, 57, 1803-1813. [CrossRef]

27. Zhao, Y.; Liu, C.; Lai, X.; Hou, S.; Zeng, X.; Li, X. Immunomodulatory activities of phlorizin metabolites in lipopolysaccharide-stimulated RAW264.7 cells. Biomed. Pharmacother. 2017, 91, 49-53. [CrossRef] 
28. Shin, S.K.; Cho, S.J.; Jung, U.J.; Ryu, R.; Choi, M.S. Phlorizin supplementation attenuates obesity, inflammation, and hyperglycemia in diet-induced obese mice fed a high-fat diet. Nutrients 2016, 8, 92. [CrossRef]

29. Alsanea, S.; Gao, M.; Liu, D. Phloretin prevents high-fat diet-induced obesity and improves metabolic homeostasis. AAPS J. 2017, 19, 797-805.

30. Cranmer-Byng, M.M.; Liddle, D.M.; De Boer, A.A.; Monk, J.M.; Robinson, L.E. Proinflammatory effects of arachidonic acid in a lipopolysaccharide-induced inflammatory microenvironment in 3T3-L1 adipocytes in vitro. Appl. Physiol. Nutr. Metab. 2015, 40, 142-154. [CrossRef]

31. Crespy, V.; Aprikian, O.; Morand, C.; Besson, C.; Manach, C.; Demigné, C.; Rémésy, C. Bioavailability of phloretin and phloridzin in rats. J. Nutr. 2001, 131, 3227-3230. [CrossRef] [PubMed]

32. Creely, S.J.; McTernan, P.G.; Kusminski, C.M.; Fisher, F.M.; Da Silva, N.F.; Khanolkar, M.; Evans, M.; Harte, A.L.; Kumar, S. Lipopolysaccharide activates an innate immune system response in human adipose tissue in obesity and type 2 diabetes. Am. J. Physiol. Endocrinol. Metab. 2007, 292, E740-E747. [CrossRef] [PubMed]

33. Oster, R.T.; Tishinsky, J.M.; Yuan, Z.; Robinson, L.E. Docosahexaenoic acid increases cellular adiponectin mRNA and secreted adiponectin protein, as well as PPAR $\gamma$ mRNA, in 3T3-L1 adipocytes. Appl. Physiol. Nutr. Metab. 2010, 35, 783-789. [CrossRef] [PubMed]

34. De Boer, A.A.; Monk, J.M.; Robinson, L.E. Docosahexaenoic acid decreases pro-inflammatory mediators in an in vitro murine adipocyte macrophage co-culture model. PLoS ONE 2014, 9, e85037. [CrossRef]

35. Lee, Y.S.; Kim, J.W.; Osborne, O.; Oh, D.Y.; Sasik, R.; Schenk, S.; Chen, A.; Chung, H.; Murphy, A.; Watkins, S.M.; et al. Increased adipocyte O2 consumption triggers HIF-1 $\alpha$, causing inflammation and insulin resistance in obesity. Cell 2014, 157, 1339-1352. [CrossRef]

36. Sekhon-Loodu, S.; Ziaullah; Rupasinghe, H. P. Docosahexaenoic acid ester of phloridzin inhibit lipopolysaccharide-induced inflammation in THP-1 differentiated macrophages. Int. Immunopharmacol. 2015, 25, 199-206. [CrossRef]

37. Lauren, D.R.; Smith, W.A.; Adaim, A.; Cooney, J.M.; Wibisono, R.; Jensen, D.J.; Zhang, J.; Skinner, M.A. Chemical composition and in vitro anti-inflammatory activity of apple phenolic extracts and of their sub-fractions. Int. J. Food Sci. Nutr. 2009, 60 (Suppl. 7), 188-205. [CrossRef]

38. Weisberg, S.P.; McCann, D.; Desai, M.; Rosenbaum, M.; Leibel, R.L.; Ferrante, A.W. Obesity is associated with macrophage accumulation in adipose tissue. J. Clin. Investig. 2003, 112, 1796-1808. [CrossRef]

39. Maury, E.; Noël, L.; Detry, R.; Brichard, S.M. In vitro hyperresponsiveness to tumor necrosis factor-alpha contributes to adipokine dysregulation in omental adipocytes of obese subjects. J. Clin. Endocrinol. Metab. 2009, 94, 1393-1400. [CrossRef]

40. Jung, S.H.; Park, S.Y.; Kim-Pak, Y.; Lee, H.K.; Park, K.S.; Shin, K.H.; Ohuchi, K.; Shin, H.K.; Keum, S.R.; Lim, S.S. Synthesis and PPAR-gamma ligand-binding activity of the new series of 2'-hydroxychalcone and thiazolidinedione derivatives. Chem. Pharm. Bull. (Tokyo) 2006, 54, 368-371. [CrossRef]

41. Rezk, B.M.; Haenen, G.R.; van der Vijgh, W.J.; Bast, A. The antioxidant activity of phloretin: The disclosure of a new antioxidant pharmacophore in flavonoids. Biochem. Biophys. Res. Commun. 2002, 295, 9-13. [CrossRef]

42. Yang, Q.; Han, L.; Li, J.; Xu, H.; Liu, X.; Wang, X.; Pan, C.; Lei, C.; Chen, H.; Lan, X. Activation of nrf2 by phloretin attenuates palmitic acid-induced endothelial cell oxidative stress via ampk-dependent signaling. J. Agric. Food Chem. 2019, 67, 120-131. [CrossRef] [PubMed]

43. Halberg, N.; Khan, T.; Trujillo, M.E.; Wernstedt-Asterholm, I.; Attie, A.D.; Sherwani, S.; Wang, Z.V.; Landskroner-Eiger, S.; Dineen, S.; Magalang, U.J.; et al. Hypoxia-inducible factor 1alpha induces fibrosis and insulin resistance in white adipose tissue. Mol. Cell. Biol. 2009, 29, 4467-4483. [CrossRef] [PubMed]

44. Monteiro, L.; Pereira, J.A.D.S.; Palhinha, L.; Moraes-Vieira, P.M.M. Leptin in the regulation of the immunometabolism of adipose tissue-macrophages. J. Leukoc. Biol. 2019, 106, 703-716. [CrossRef] [PubMed]

45. O’'Rourke, R.W.; White, A.E.; Metcalf, M.D.; Olivas, A.S.; Mitra, P.; Larison, W.G.; Cheang, E.C.; Varlamov, O.; Corless, C.L.; Roberts, C.T.; et al. Hypoxia-induced inflammatory cytokine secretion in human adipose tissue stromovascular cells. Diabetologia 2011, 54, 1480-1490. [CrossRef]

46. Fujisaka, S.; Usui, I.; Ikutani, M.; Aminuddin, A.; Takikawa, A.; Tsuneyama, K.; Mahmood, A.; Goda, N.; Nagai, Y.; Takatsu, K.; et al. Adipose tissue hypoxia induces inflammatory M1 polarity of macrophages in an HIF-1 $\alpha$-dependent and HIF-1 $\alpha$-independent manner in obese mice. Diabetologia 2013, 56, 1403-1412. [CrossRef] 
47. Jetten, N.; Verbruggen, S.; Gijbels, M.J.; Post, M.J.; De Winther, M.P.; Donners, M.M. Anti-inflammatory M2; but not pro-inflammatory M1 macrophages promote angiogenesis in vivo. Angiogenesis 2014, 17, 109-118. [CrossRef]

48. Tamori, Y.; Masugi, J.; Nishino, N.; Kasuga, M. Role of peroxisome proliferator-activated receptor-gamma in maintenance of the characteristics of mature 3T3-L1 adipocytes. Diabetes 2002, 51, 2045-2055. [CrossRef]

49. Suganami, T.; Nishida, J.; Ogawa, Y. A paracrine loop between adipocytes and macrophages aggravates inflammatory changes: Role of free fatty acids and tumor necrosis factor alpha. Arter. Thromb. Vasc. Biol. 2005, 25, 2062-2068. [CrossRef]

(C) 2020 by the authors. Licensee MDPI, Basel, Switzerland. This article is an open access article distributed under the terms and conditions of the Creative Commons Attribution (CC BY) license (http://creativecommons.org/licenses/by/4.0/). 